\title{
Neglect of STIs and infertility undermines family planning programmes
}

\author{
Cicely Marston, ${ }^{\circledR}$ Suzanna C Francis $^{\oplus 2}$
}

${ }^{1}$ Public Health, Environments and Society, London School of Hygiene and Tropical Medicine Faculty of Public Health and Policy, London, UK

${ }^{2}$ MRC Tropical Epidemiology Group, London School of Hygiene and Tropical Medicine, London, UK

\section{Correspondence to} Professor Cicely Marston, Public Health, Environments, and Society, London School of Hygiene and Tropical Medicine Faculty of Public Health and Policy, London WC1E 7HT, UK; Cicely.Marston@Ishtm.ac.uk

Received 14 November 2018 Revised 24 July 2019

Accepted 9 September 2019

\section{Check for updates}

(c) Author(s) (or their employer(s)) 2019. No commercial re-use. See rights and permissions. Published by BMJ.

To cite: Marston C, Francis SC. BMJ Sex Reprod Health Published Online First: [please include Day Month Year]. doi:10.1136/

bmjsrh-2018-200270
Women's concerns about infertility and return to fertility after using hormonal contraceptives are well documented and are often dismissed as 'myths'. Yet in settings with uncontrolled epidemics of sexually transmitted infections (STIs) among young people, using contraceptives to delay childbearing may coincide with being infected with an STI. Chlamydia in particular is an important cause of tubal factor infertility.

The extent of STI prevalence has long been unmeasured in low-income and middle-income settings. Recent studies, however, have found a major uncontrolled chlamydia epidemic among young people in South Africa, ${ }^{12}$ suggesting that in other similar contexts there is also likely to be an unmeasured epidemic. This high prevalence of undiagnosed and untreated chlamydia is likely to be causing widespread fertility problems.

Fears about future infertility are some of the most widely cited reasons for avoiding highly effective contraceptives, and are often characterised in the literature as 'misconceptions' or 'myths' because the methods themselves are unlikely to cause infertility directly. ${ }^{3}$ Infertility is devastating anywhere in the world and for many can cause economic deprivation and social isolation as well as personal grief. For example, while pregnancy can confer adult status on women, ${ }^{4}$ studies from Nigeria ${ }^{4}$ and Tanzania $^{5}$ report women who had never given birth being characterised as 'useless'. Infertile women in Ghana can face severe social stigma, marital strain and a range of mental health difficulties. ${ }^{6}$ It is not surprising that future fertility is a key priority for many women, and real and perceived threats to this can undermine family planning programmes.

The response in many programmes has been to give information to address women's perceived ignorance about contraceptive methods. Yet when women speak about their lives and fertility choices (as they have done in our studies in Ghana ${ }^{78}$ and Nepal, ${ }^{9}$ for instance), they are often highly knowledgeable; the explanations for their use or non-use of contraceptives are bound up in the complexities of their lives as a whole, such as wishing to delay pregnancies while completing education, or being under pressure from their families to avoid certain contraceptives. ${ }^{7}$

Crucially, though, there is a hitherto ignored factor: decisions about fertility may take place in a context where the threat of infertility is all too real. For instance, in settings where women give birth in early adulthood then wait to have subsequent children, they may be infected with STIs that reduce their fertility while attempting to space their births using hormonal contraceptive methods, but not condoms. If this is the case, because they will be unaware of undiagnosed, asymptomatic STIs, they or those around them might assume that the contraceptives 'caused' later fertility problems. In a setting with high chlamydia prevalence, other women will likely experience similar fertility problems, and this might contribute to a sense that contraceptive methods cause infertility.

There is a solution: using women's own priorities as a starting point will help to develop sexual and reproductive health programmes that are more attractive and win people's trust. We still have a long way to go if we are to measure STI prevalence accurately in low-income and middle-income countries and set up effective control strategies-especially for chlamydia where infection control is challenging even in high-income settings.

Five areas can be addressed immediately:

First, we must take infertility seriously. In high fertility settings infertility may not even be considered a problem by funders prioritising population control. Fertility remains high in many countries, particularly in West, Central and East Africa, ${ }^{10}$ and infertility may be given low priority 
where healthcare resources are scarce, even if it is a high priority for the individuals and families the programmes are ostensibly designed to serve.

Second, we must recognise that messaging from family planning and STI programmes may be in conflict. Women are generally unwilling to use dual protection, that is, use condoms and more reliable contraceptives at the same time. ${ }^{11}$ Using effective contraceptives may therefore decrease condom use, increasing the risk of STIs and increasing women's risk of infertility from STI infection.

Third, we need to stop splitting research into silosin this case, family planning split from STI prevention and treatment; this reflects how global health research is organised, but we must look more holistically at the issues individuals and families face. Funders have an important role to play in driving this change, for instance by insisting on person-centred research. This would require multiple disciplines to work together and community priorities to be incorporated in research question setting.

Fourth, we must address the failure to prioritise women's established right to control their fertility in the fullest sense. Managing fertility means having children when individuals want to have them as well as avoiding pregnancy when they do not. Yet in low-income and middle-income settings, programmes focus almost exclusively on the latter, with infertility often ignored completely. Poverty and gender discrimination, along with lack of access to a range of contraceptives, safe abortion and STI prevention and treatment, undermine individuals' right to decide freely whether, when and how many children to have.

Last, we must improve diversity among researchers in this field. The recent work we discussed here has been led by women, who may well ask different sets of questions; increasing diversity within science makes good scientific sense, and it is likely that it will help us see other perennial problems in a new light.

In contexts where there is high and poorly understood risk to fertility, it is unwise to depict women simply as ignorant when they associate hormonal methods with infertility. It would be fairer to acknowledge that as scientists we have not considered carefully enough why these beliefs might be held in the first place-and this may also apply in a wider range of settings than we have considered here. Meanwhile, women continue to endure infertility from what should be entirely avoidable and treatable causes. The impact on population growth of infertility is unclear. Counterintuitively, it is possible that by addressing fertility problems in programmes, fertility at a population level might be reduced, as individuals become confident that they can use effective contraceptive without experiencing devastating infertility. By putting women's priorities at the heart of research and programming, these 'counterintuitive' relationships between treating infertility and also meeting unmet need for contraception will start to make sense.

Twitter Cicely Marston@cicely and Suzanna C Francis@ SuzannaCarterF1

Contributors $\mathrm{CM}$ conceived the idea for this article and drafted it. SCF contributed to conceptualisation, provided expert input and contributed to drafting. Both authors agree with and approve the final content.

Funding SCF received salary support from the UK Medical Research Council (MRC) and the UK Department for International Development (DFID) under the MRC/DFID Concordat agreement and also a part of the EDCTP2 programme supported by the European Union (MR/ N023692/1; MR/K012126/1). The funders had no role in the development of this commentary.

Competing interests None declared.

Patient consent for publication Not required.

Provenance and peer review Not commissioned; externally peer reviewed.

\section{REFERENCES}

1 Francis SC, Mthiyane TN, Baisley K, et al. Prevalence of sexually transmitted infections among young people in South Africa: a nested survey in a health and demographic surveillance site. PLoS Med 2018;15:e1002512.

2 Torrone EA, Morrison CS, Chen P-L, et al. Prevalence of sexually transmitted infections and bacterial vaginosis among women in sub-Saharan Africa: an individual participant data meta-analysis of $18 \mathrm{HIV}$ prevention studies. PLoS Med 2018;15:e1002511.

3 Ochako R, Mbondo M, Aloo S, et al. Barriers to modern contraceptive methods uptake among young women in Kenya: a qualitative study. BMC Public Health 2015;15:118.

4 Hollos M, Whitehouse B. Women in limbo: life course consequences of infertility in a Nigerian community. Hum Fertil 2014;17:188-91.

5 Hollos M, Larsen U. Motherhood in sub-Saharan Africa: the social consequences of infertility in an urban population in northern Tanzania. Cult Health Sex 2008;10:159-73.

6 Fledderjohann JJ. 'Zero is not good for me': implications of infertility in Ghana. Hum Reprod 2012;27:1383-90.

7 Marston C, Renedo A, Nyaaba GN. Fertility regulation as identity maintenance: understanding the social aspects of birth control. J Health Psychol 2018;23:240-51.

8 Marston C, Renedo A, Nyaaba GN, et al. Improving the measurement of fertility regulation practices: findings from qualitative research in Ghana. Int Perspect Sex Reprod Health 2017;43:111-9.

9 Abriti A, Marston C, Fairfax J, Maskey S, Giri S, Regmi S. Mobilization of FCHVs to Disseminate family planning messages using interpersonal communication (IPC) in Myagdi district, Nepal. Kathmandu HERD International and Mott MacDonald Ltd; 2016.

10 United Nations. Trends in contraceptive use worldwide 2015. New York, NY United Nations (Department of Economic and Social Affairs); 2015.

11 Lopez LM, Otterness C, Chen M, et al. Behavioral interventions for improving condom use for dual protection. Cochrane Database Syst Rev 2013;(10):CD010662. 